\title{
Cleaner Production Assessment of Fast Bordeaux GP Base
}

\author{
Mausumi Mukhopadhyay ${ }^{1}$ and Rashmita D. Patel ${ }^{2}$ \\ ${ }^{1}$ Department of Chemical Engineering, Sardar Vallabhbhai National Institute of Technology, Surat, Gujarat 395007, India \\ ${ }^{2}$ Department of Chemical Engineering, Sarvajanik College of Engineering and Technology, Surat, Gujarat 395001, India
}

Correspondence should be addressed to Mausumi Mukhopadhyay, mmu@ched.svnit.ac.in

Received 8 September 2010; Revised 7 April 2011; Accepted 11 April 2011

Academic Editor: Ashraf Aly Shehata

Copyright (C 2011 M. Mukhopadhyay and R. D. Patel. This is an open access article distributed under the Creative Commons Attribution License, which permits unrestricted use, distribution, and reproduction in any medium, provided the original work is properly cited.

\begin{abstract}
The pilot plant study of cleaner production (CP) process of a dyes intermediate, Fast Bordeaux GP Base (2-nitro-p-anisidine), is presented in this work. The existing production process with acetic anhydride as raw material generates highly polluting (high chemical oxygen demand), huge-volume effluent, and thus the treatment is expensive. In the proposed process, raw material acetic anhydride in acetylation step is replaced with acetic acid. The reaction conditions like reaction time $(3 \mathrm{~h})$, temperature $\left(120^{\circ} \mathrm{C}\right)$ and molar ratio of $\mathrm{p}$-anisidine and acetic acid $(1: 3.58)$ are optimized in the laboratory scale and implemented in pilot plant. The extent of conversion has been monitored by nitrite value test, and purity of product mixture is measured with thin-layer chromatography (TLC). The acidic wastewater quantity is dramatically reduced by incorporating recycling in washing scheme, and thus water consumption is reduced. Reduction in wastewater generation and reduction/elimination of treatment cost is also observed. Chemical oxygen demand (COD) of the effluent stream is reduced by the recovery of by-products sodium acetate and spent acid. The technoeconomical feasibility studies show that the proposed CP options are highly economical and environmental friendly.
\end{abstract}

\section{Introduction}

Progress in the understanding of the phenomena of pollution and modifications to the ecosystem has revealed that environmental impacts must be seen from a product and process design point of view $[1,2]$. Therefore, environmental management has concentrated on the development of production system by a new approach of pollution prevention or cleaner production. It is closely connected with efficient utilization of materials and energy to eliminate as much as possible toxic substances, reducing quantity and toxicity of emissions and waste before these substances leave the process [3].

The high wastewater production of different industrial processes sustains high treatment cost and requires large effluent treatment systems. To reduce the impact of high water consumption, industries have been searching for alternative methods by adopting systems and technologies to control and treat (clean-up or end-of-pipe) the pollutant emissions generated by production processes. These pollution techniques require additional energy and materials, and disposal of resulting waste has negative influence on the society $[4,5]$. Currently, there is a focus in industry towards the use of methodologies for controlling pollution at source, particularly through cleaner production. Cleaner production seems to offer a more effective approach to environmental improvement than the traditional methods of applying "clean-up" or "end-of-pipe" controls. The basic idea of cleaner production is that it makes more sense to eliminate a problem rather than trying to rectify the problem [6]. Various cleaner production approaches that can be applied in production processes include raw material substitution [7], equipment modification [8], technological modification [9], by-product recovery, and recycling [10]. The use of the above-mention methodologies decreases the amount of water used in industrial processes, means reduced costs for fresh water, wastewater, and discharge.

Fast Bordeaux GP base (2-nitro 4-methoxy aniline) is an intermediate dye used for yarn dyeing as raw material for pigments and for printing of cotton. The details of Fast Bordeaux GP Base are given in Table 1. The main target of this work is to reduce wastewater generation and chemical oxygen demand (COD) reduction in a Fast Bordeaux GP Base (dye intermediate) production plant. In order to reduce COD and wastewater generation, the $\mathrm{CP}$ options like raw material 
TABle 1: Details of fast bordeaux GP base.

\begin{tabular}{|c|c|c|c|}
\hline & & Molecular structure & Uses \\
\hline Trade name & Fast Bordeaux GP Base & & (i) Cotton and yarn dyeing \\
\hline Chemical name & 2-nitro-4-methoxyaniline & $\mathrm{NH}_{2}$ & (ii) Intermediate for pigments \\
\hline Molecular formula & $\mathrm{C}_{7} \mathrm{H}_{8} \mathrm{~N}_{2} \mathrm{O}_{3}$ & & (iii) Printing for cotton. \\
\hline Molecular weight & 168 & & \\
\hline Appearance & Amorphous, reddish orange coloured. & & \\
\hline Melting point & $129^{\circ} \mathrm{C}$ & & \\
\hline CAS no. & $96-96-8$ & $\mathrm{OCH}_{3}$ & \\
\hline
\end{tabular}

substitution in acetylation step (acetic anhydride with acetic acid), recovery of by-product (sodium acetate and spent acid), and recycling in washing scheme have been investigated. The acetylation reaction conditions such as reaction time, temperature, molar ratio of reactants have been optimized in the lab scale and applied in pilot plant scale.

\section{Conventional Production Process}

The schematic diagram of conventional production process of Fast Bordeaux GP Base is presented in Figure 1. The batch size is $400 \mathrm{~kg}$ of p-anisidine. The compound p-anisidine has been acetylated with acetic anhydride (temperature maintained at $60^{\circ} \mathrm{C}$ ) in an open reactor followed by neutralization with soda ash. This process has been generated with high amount of sodium acetate as by-product and contributing to high COD. The neutralized reaction mass, the wet cake, has been filtered and subjected to nitration with nitric acid in the presence of small quantity of sodium nitrite (to enhance the nitration reaction). The washed cake after nitration was hydrolyzed with caustic flakes and washed with huge quantity of fresh water. Finally, the hydrolyzed wet cake was neutralized with hydrochloric acid and has been washed, filtered, and dried in rotary dryer [11]. The percentage yield of Fast Bordeaux GP Base has been evaluated as $90 \%$. Approximately $730 \mathrm{~kL} / \mathrm{month}$ of wastewater (COD: $2,00,000 \mathrm{mg} / \mathrm{L}$ and acidity $5 \%$ as $\mathrm{HNO}_{3}$ ) [12] has been generated. The cleaner production assessment has been adopted to overcome these problems.

\section{Methodology}

The detailed in-plant assessment was carried out, and various waste sources were evaluated from the theoretical consideration and actual material balance. The excess raw materials like acetic anhydride, nitric acid, caustic flakes, and soda ash as well as the by-product like sodium acetate were going into effluent treatment plant (ETP) as waste stream. Therefore, various CP options were generated for the waste minimization.

3.1. Raw Material Substitution. The use of acetic anhydride as an acetylating agent for acetylation of p-anisidine produced one mole of acet-p-anisidine and one mole of sodium acetate with soda ash. Excess of acetic anhydride was used to make the reaction mixture slurry. By-product sodium acetate

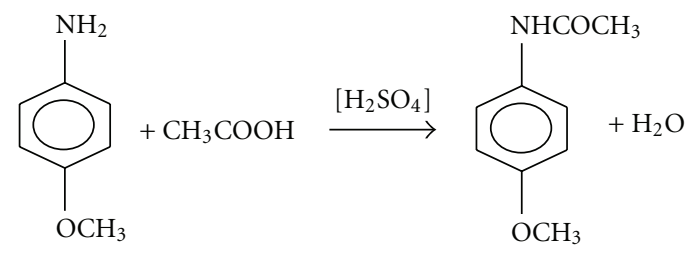

Scheme 1: Reaction scheme for acetylation of $\mathrm{p}$-anisidine with acetic acid.

and excess raw material acetic anhydride were discharged into the waste stream and in turn contributes high COD.

To solve this problem, a new method of acetylation using acetic acid in the presence of sulphuric acid (catalyst) was proposed, and the reaction conditions like reaction time, temperature and molar ratio of reactant were investigated. The chemical reaction involved acetylation with acetic acid as shown in Scheme 1.

3.2. Experiments. The lab experiments were carried out in a round-bottom conical flask equipped with stirring facility. Molar ratio of $1: 3.58$ glacial acetic acid and panisidine was mixed to prepare homogeneous solutions. $1 \mathrm{~mL}$ of concentrated sulphuric acid was used as a catalyst. Samples of about $2 \mathrm{~mL}$ were withdrawn from the reactor at different intervals of time and analyzed. The extent of conversion was monitored by nitrite value test (Standard Methods, AWWA, 1995), and purity of product mixture was measured with thin-layer chromatography, (TLC) having $0.25 \mathrm{~mm}$ thickness silica gel $\mathrm{G}$ coated Al plates (Merck). The spots were visualized by exposing the dry plates in UV light using toluene:methanol $(19: 1 \mathrm{v} / \mathrm{v}$, upper layer) as a solvent. After the complete conversion, excess of acetic acid was distilled out by distillation and the residue was taken for nitration stage. The distillate (acetic acid) was recycled back for acetylation in the next batch. The reaction conditions investigated were reaction time, temperature, and molar ratio of reactants.

The reaction was initially carried out at different time interval to know the equilibrium time for this proposed reaction. The reaction was carried out at different temperatures $80,90,100,110$, and $120^{\circ} \mathrm{C}$ for $3 \mathrm{~h}$ to incur the impact of temperature on the proposed reaction. The extent of conversion at various molar ratios of $1: 1.75,1: 2,1: 3$, $1: 4$, and $1: 5$ at a fixed time of $3 \mathrm{~h}$ and temperature of $120^{\circ} \mathrm{C}$ was also investigated. After completion of acetylation 

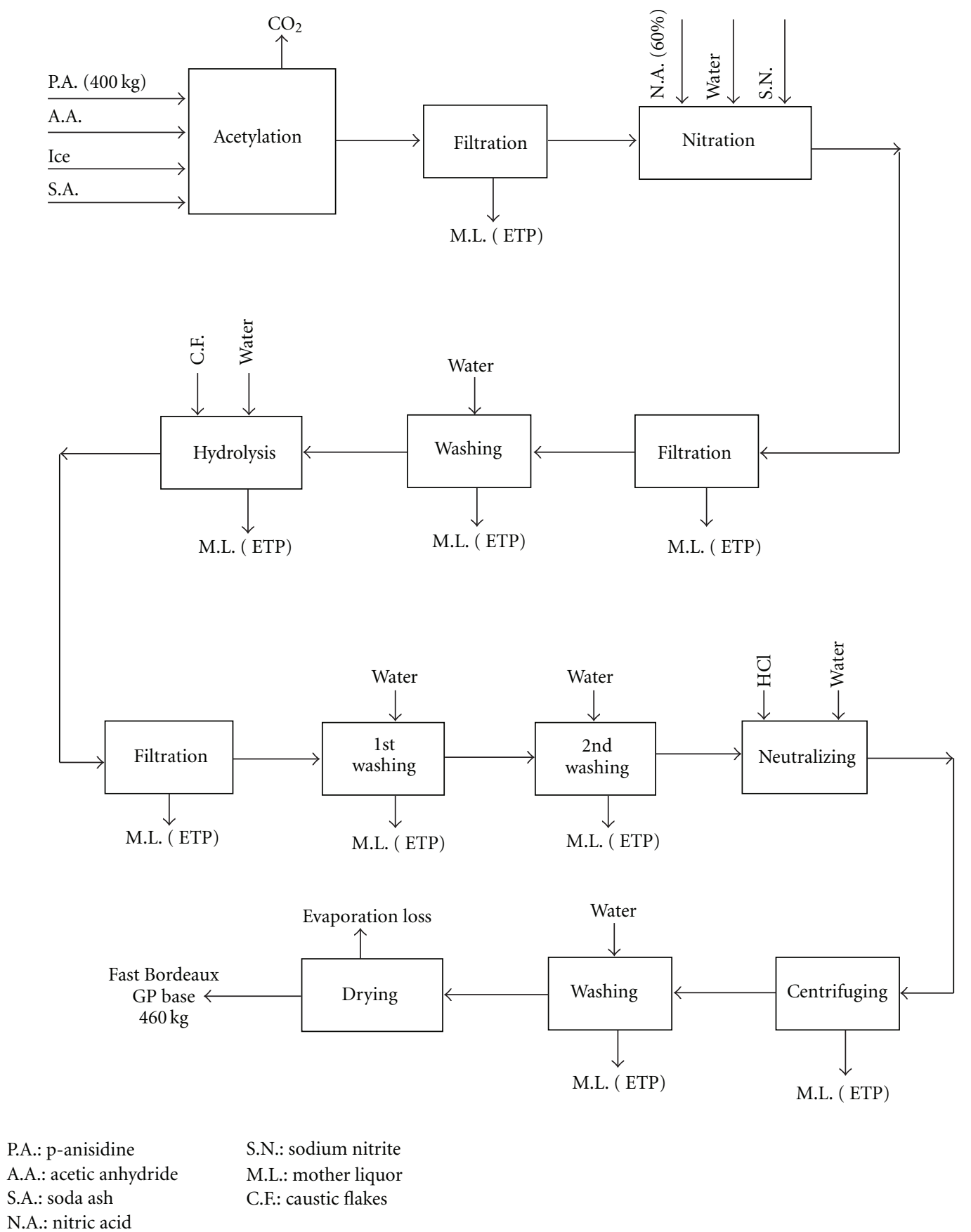

S.N.: sodium nitrite

M.L.: mother liquor

C.F.: caustic flakes

FIGURE 1: Conventional prod ${ }^{\mathrm{n}}$. Process of fast bordeaux GP base (batch $400 \mathrm{~kg}$ of p-anisidine).

reaction, excess of acetic acid present in the reaction mass was recovered by distillation at $120^{\circ} \mathrm{C}$.

\section{Result and Discussion}

According to theoretical calculation, 1:1 molar ratio (panisidine to acetic acid) was required for the conversion of $\mathrm{p}$-anisidine to acet-p-anisidine, but this was not producing homogeneous solution; therefore, the molar ratio of $1: 3.58$ was selected for this reaction, which produced homogeneous solution. The reaction was carried out at different temperatures: $80,90,100,110$, and $120^{\circ} \mathrm{C}$ for $3 \mathrm{~h}$. The extent of conversion at various reaction temperatures shown in Figure 2. The conversion of $\mathrm{p}$-anisidine to its acetyl product was increased with the increase in time and temperature as shown in Figure 2. The highest conversion of $99 \%$ was observed in $3 \mathrm{~h}$ at $120^{\circ} \mathrm{C}$. The extent of conversion at various molar ratios of $1: 1.75,1: 2,1: 3,1: 4$, and $1: 5$ at a fixed time of $3 \mathrm{~h}$ and temperature of $120^{\circ} \mathrm{C}$ was shown in Figure 3. It showed that the percentage conversion was 
TABLE 2: Acidity and sodium acetate in filtrate and washed water in nitration and hydrolysis step.

\begin{tabular}{lcccccc}
\hline & \multicolumn{3}{c}{ Acidity $\left(\%\right.$ w/v as $\left.\mathrm{HNO}_{3}\right)$} & of nitration & \multicolumn{3}{c}{ Sodium acetate $(\%$ w/v) of hydrolysis } \\
& Batch-1 & Batch-2 & Batch-3 & Batch-1 & Batch-2 & Batch-3 \\
\hline Filtrate & 20 & 20.1 & 19.8 & 7.5 & 19.2 & 8.1 \\
Washed water I & 7.2 & 8.4 & 9 & 2.5 & 3.7 & 8.3 \\
Washed water II & 2.8 & 4 & 1.6 & 0 & 4.0 \\
Washed water III & 0 & 1.2 & 0.5 & 0 & 1.2 \\
Washed water IV & 0 & 0.3 & & 0.3 & 0.4 \\
\hline
\end{tabular}

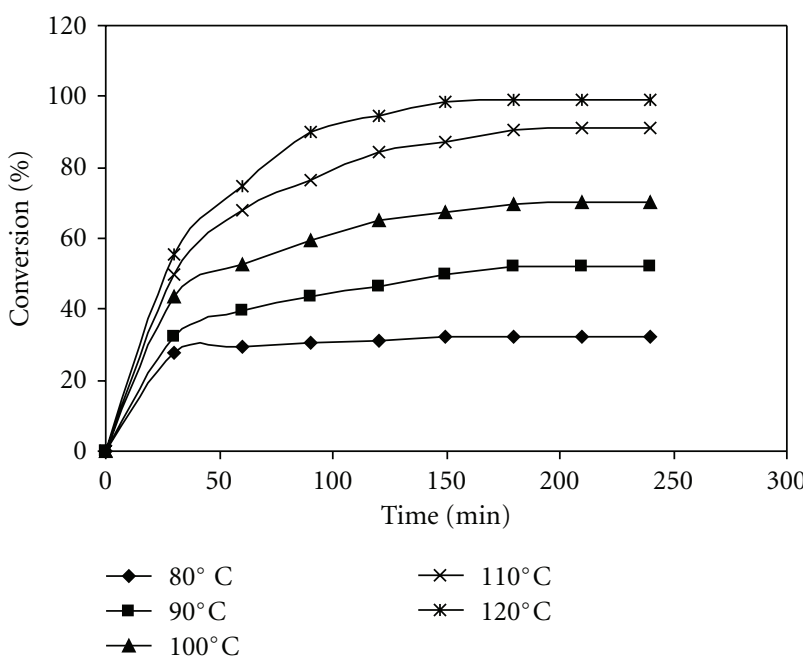

Figure 2: Conversion versus time at different temperature with molar ratio of $1: 3.58$ in $3 \mathrm{~h}$.

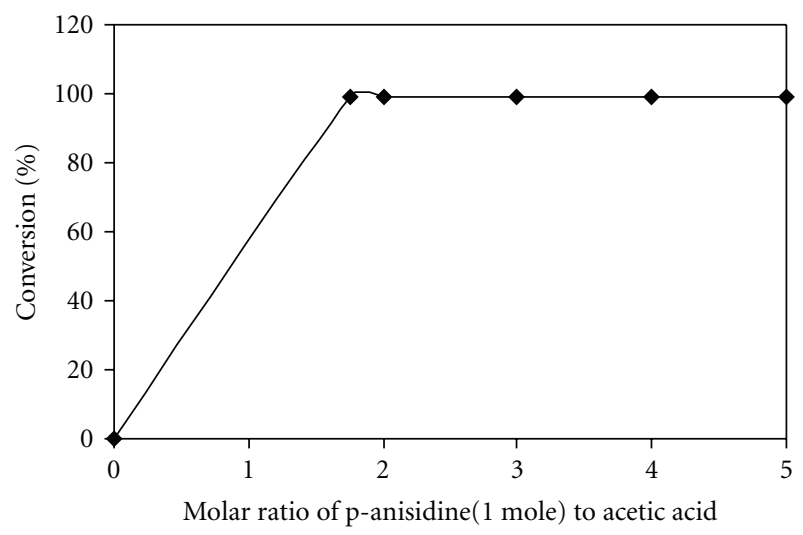

Figure 3: Conversion versus molar ratio of p-anisidine and acetic acid at $120^{\circ} \mathrm{C}$ in $3 \mathrm{~h}$.

unchanged with varying the molar ratio higher than $1: 1.75$. After completion of acetylation reaction, excess of acetic acid present in the reaction mass was recovered by distillation at $120^{\circ} \mathrm{C}$. The time required for distillation of acetic acid was shown in Figure $4.125 \mathrm{~mL}$ of distillate was recovered within $30 \mathrm{~min}$. With further increase in time, the quantity of distillate recovered was negligible. The overall reaction condition for acetylation with acetic acid was at temperature of $120^{\circ} \mathrm{C}$, and $1: 3.58$ molar ratio of $\mathrm{p}$-anisidine to acetic acid

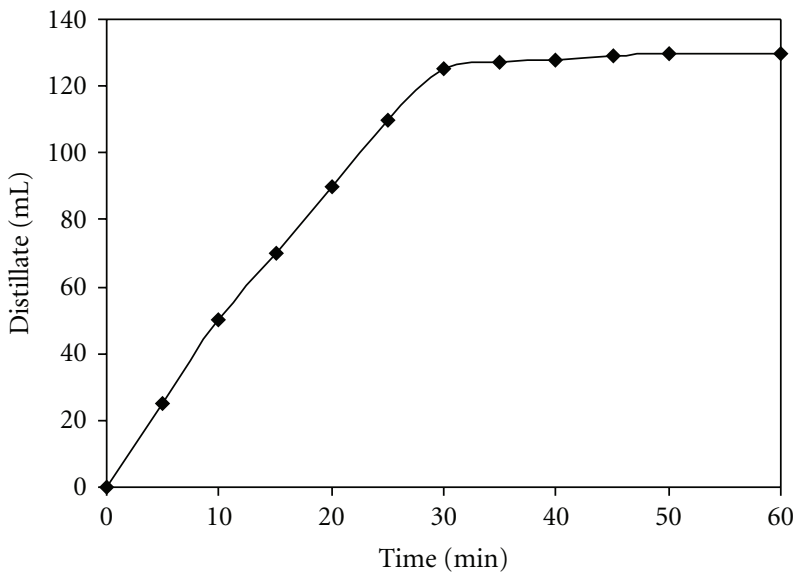

FIGURe 4: Distillate quantity versus time for distillation of excess acetic acid.

to make homogeneous solution, and reaction time was $3.5 \mathrm{~h}$ (combining acetylation and excess of acetic acid distillation time).

In the conventional production process, nitric acid was used in excess, and thus sodium acetate was produced during the nitration and hydrolysis stage, respectively, which contributed acidity and COD to the effluent. Huge quantity of fresh water was used for the washing of wet cake throughout the process. Stage-wise washing scheme was suggested to overcome these drawbacks for batch operation. The newly developed washing scheme with recovery and recycling options was as shown in Figure 5 . The washed water was segregated in different stages ( $1 / 4$ of the original quantity) instead of washing with huge quantity of fresh water at once. The first-batch first-stage washing containing concentrated mass of spent acid (nitration step) and sodium acetate (hydrolysis step) was stored separately to sell as a byproduct to the respective users. The second-stage washings of the first batch was utilized in the first-stage washing of next batch, third-stage washings of first batch were utilized for the second stage washing of next batch and so on.

In a typical run, residue from acetylation stage was subjected to nitration with nitric acid, water, and sodium nitrite at temperature of $40^{\circ} \mathrm{C}-45^{\circ} \mathrm{C}$. The progress of reaction was monitored by TLC. Upon completion of nitration, the reaction mass was filtered into vacuum filter. The mother liquor was collected in a separate collection tank. The wet cake was washed with fresh water for four times. The water 


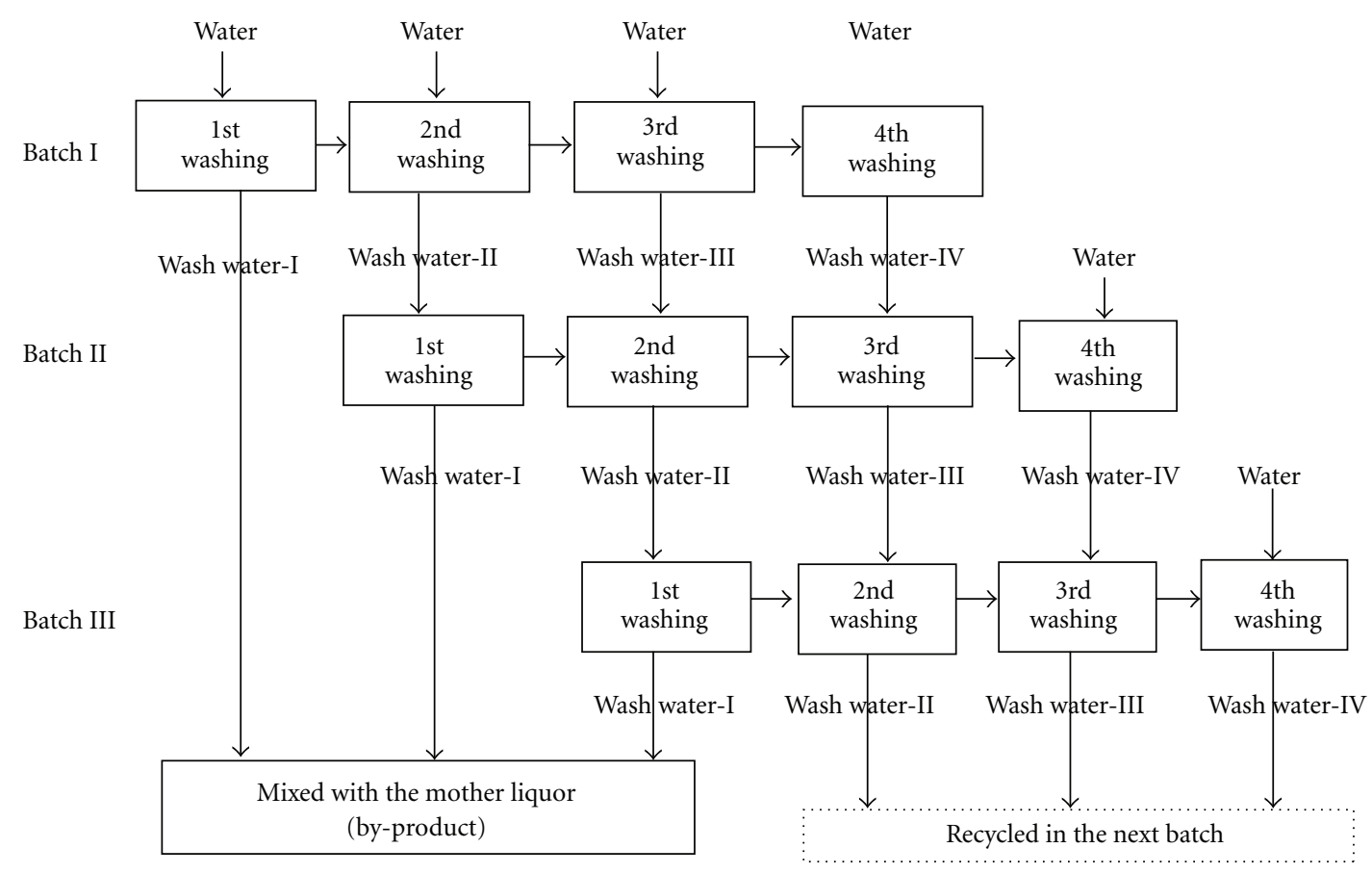

FIGURE 5: Modified washing scheme with recovery and recycling option.

TABLE 3: The comparison of existing and proposed practice.

Sr. no.

Process steps

Water consumption in $\mathrm{kl}$ Effluent generation in $\mathrm{k}$

Recovered by-product

Existing process: Reaction temperature was maintained to $70^{\circ} \mathrm{C}$ by the addition of ice and reaction time of $3.5 \mathrm{~h}(3 \mathrm{~h}$ for acetylation and $30 \mathrm{~min}$ for neutralization with soda ash); yield was $90 \%$.

\begin{tabular}{lcccc}
\hline$(1)$ & Acetylation & Nil & 76 & - \\
$(2)$ & Nitration & 225 & 258 & - \\
$(3)$ & Hydrolysis & 275 & 280 & - \\
$(4)$ & Neutralization & 10 & 116 & - \\
\hline Total & & 510 & 729 & -
\end{tabular}

Proposed process: Reaction temperature was $120^{\circ} \mathrm{C}$, in reaction time of $31 / 2 \mathrm{~h}(3 \mathrm{~h}$ for acetylation and 30 min for distillation of excess acetic acid); yield was 95\%.

\begin{tabular}{lcccc}
\hline$(1)$ & Acetylation & Nil & Nil & Spent acid (15\%) \\
$(2)$ & Nitration & 75 & Nil & Sodium acetate (15\%) \\
$(3)$ & Hydrolysis & 125 & Nil & - \\
$(4)$ & Neutralization & 10 & 116 & - \\
\hline Total & & 210 & 116 & - \\
\hline
\end{tabular}

of washings was collected separately and recycled in the next batches. The filtrate (mother liquor) and washed water of different washings was analyzed for the acidity of effluent. The washed cake was hydrolyzed with caustic flakes and water, at $76-77^{\circ} \mathrm{C}$. The progress of reaction was monitored by TLC. Upon completion of the reaction, the reaction mass was filtered in vacuum filter. The mother liquor was collected separately in collection tank. The wet cake was washed with fresh water for four times, and the water of washings was collected separately and recycled in the next batches. The filtrate (mother liquor) and washed water of different washings was analyzed for the sodium acetate content. The percentage of acidity and sodium acetate in filtrate and washed water of three batches of nitration and hydrolysis was shown in Table 2 . The acidity and sodium acetate (separated as by-product) content of mother liquor and 1 st washed water was 14-15\%. In the hydrolyzed washed cake, hydrochloric acid and water were added to neutralize. The neutralized reaction mass was then filtered by vacuum filter and washed with water. The total quantity of filtrate and washed water from this stage was much less compared to the conventional method. The purity of the product was checked by TLC, and the yield of the product was determined. The washed wet cake was dried and weighed. The effluent with COD: 700-850 mg/L, pH: 7, and color: 86 hazan was obtained. The wastewater with these characteristics was 

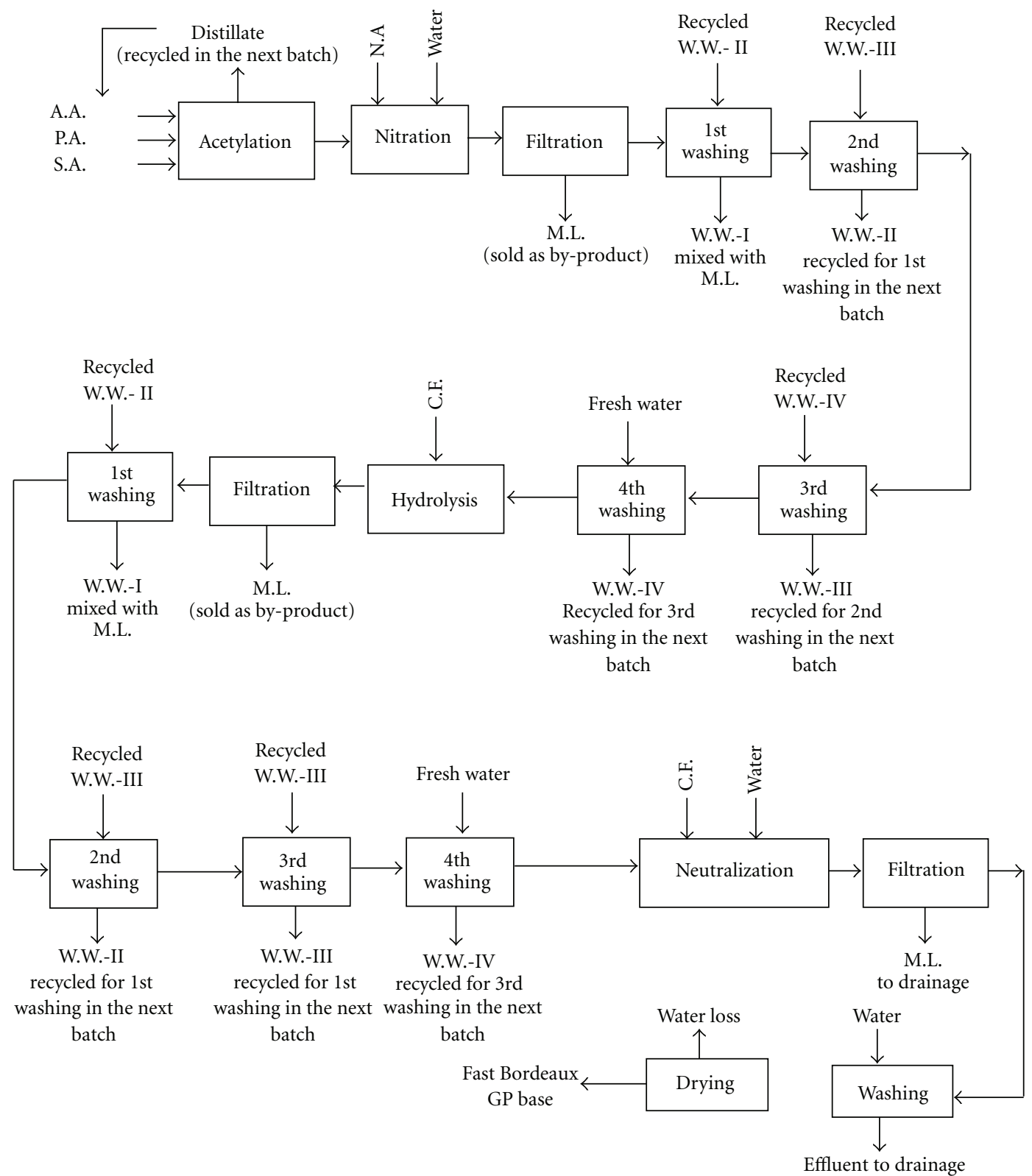

$\begin{array}{ll}\text { P.A.: p-anisidine } & \text { N.A.: nitric acid } \\ \text { A.A.: acetic acid } & \text { M.L.: mother liquor } \\ \text { S.A.: soda ash } & \text { C.F.: caustic flakes }\end{array}$

FIGURE 6: Proposed process flow diagram for the manufacturing of fast bordeaux GP base after CP.

discharged in a drainage system of industrial estate without any treatment. The percentage yield of Fast Bordeaux GP Base after cleaner production assessment increased from $90 \%$ to $95 \%$.

\section{Detailed Proposed Process}

The modified process flow diagram after accounting the technical viable options is shown in Figure 6. The reaction condition, water consumption, effluent generation, and byproduct generation of existing and proposed processes are compared and summarized in Table 3 . Water consumption is reduced by $300 \mathrm{kl}$, and effluent generation is reduced by $613 \mathrm{kl}$.

\section{Conclusions}

Cleaner production techniques of raw material substitution and recovery and recycling operation have been used in the current study for the manufacturing of Fast Bordeaux GP Base. The following conclusions can be drawn.

(1) The existing production process is highly polluting and expensive due to the use of raw material acetic 
anhydride and also due to the disproportionate addition of raw materials.

(2) The proposed raw material substitution of acetic anhydride with acetic acid in acetylation step can reduce (from $76 \mathrm{kl}$ to nil, refer to Table 3 ) effluent generation.

(3) The proposed recovery and recycling operation in nitration and hydrolysis steps not only harvest the byproducts of spent acid (in nitration) and sodium acetate (in hydrolysis) but also eliminate the effluent generation in the process step and the selling of byproducts can increase the economic benefits.

(4) The proposed production process further eliminates the requirement of effluent treatment of neutralization step due to the decrease in pollutant amount in effluent.

(5) The proposed options further contribute in saving compared to the existing practice besides increasing the \% yield from 90 to 95 .

(6) In view of the above findings, it can be concluded that the proposed cleaner production options are technoeconomically viable and ecofriendly.

\section{References}

[1] T. Shen, Industrial Pollution Prevention, Springer, New York, NY, USA, 1995.

[2] R. Wedford, Environmental Strategy and Sustainable Development, Routledge, London, UK, 1995.

[3] S. Ghazinoory, "Cleaner production in Iran: necessities and priorities," Journal of Cleaner Production, vol. 13, no. 8, pp. 755-762, 2005.

[4] E. Cagno, P. Trucco, and L. Tardini, "Cleaner production and profitability: analysis of 134 industrial pollution prevention (P2) project reports," Journal of Cleaner Production, vol. 13, no. 6, pp. 593-605, 2005.

[5] K. A. Zotter, "End-of-pipe versus process-integrated water conservation solutions: a comparison of planning, implementation and operating phases," Journal of Cleaner Production, vol. 12, no. 7, pp. 685-695, 2004.

[6] A. Clayton, G. Spinatdi, and R. Williams, Policies for Cleaner Technology, Eartscan Publications, London, UK, 1999.

[7] Y. Qian, Y. Chen, Y. Jiang, and L. Zhang, "A clean production process of sodium chlorite from sodium chlorate," Journal of Cleaner Production, vol. 15, no. 10, pp. 920-926, 2007.

[8] J. Oral, R. Puchyr, Z. Hajny, P. Stehlik, L. Bebar, and J. Sikula, "Processing of waste from pulp and paper plant," Journal of Cleaner Production, vol. 13, no. 5, pp. 509-515, 2005.

[9] G. Y. Abbasi and B. E. Abbassi, "Environmental assessment for paper and cardboard industry in Jordan-a cleaner production concept," Journal of Cleaner Production, vol. 12, no. 4, pp. 321-326, 2004.

[10] T. H. Kim, C. Park, and S. Kim, "Water recycling from desalination and purification process of reactive dye manufacturing industry by combined membrane filtration," Journal of Cleaner Production, vol. 13, no. 8, pp. 779-786, 2005.

[11] K. Venkatraman, The Chemistry of Synthetic Dyes, Academic Press, New York, NY, USA, 1952.
[12] APHA, AWWA, and WPCF, Standard Methods for the Examination of Water and Wastewater, Publication Office American Public Health Association, Washington, DC, USA, 19th edition, 1995. 


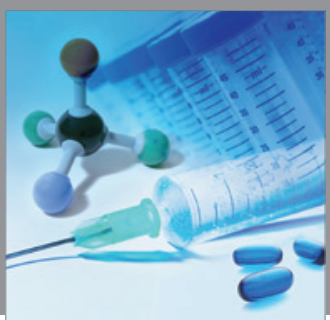

International Journal of

Medicinal Chemistry

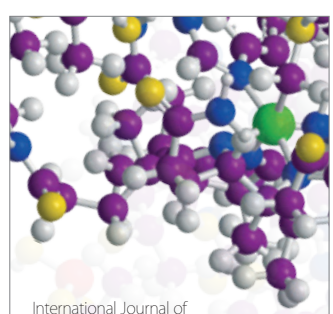

Carbohydrate Chemistry

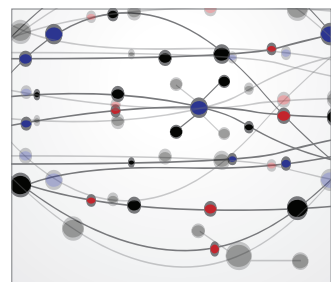

The Scientific World Journal
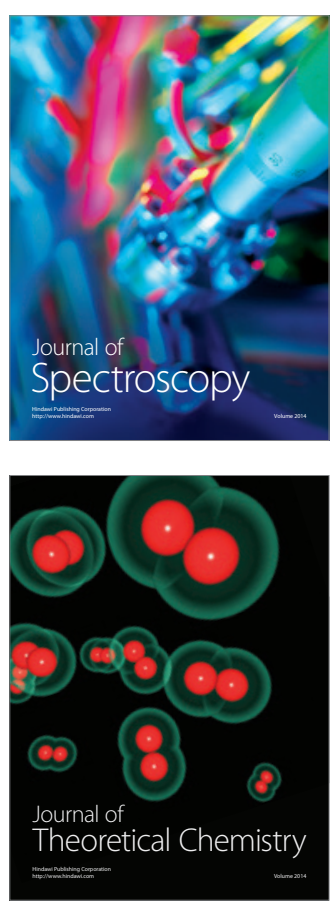
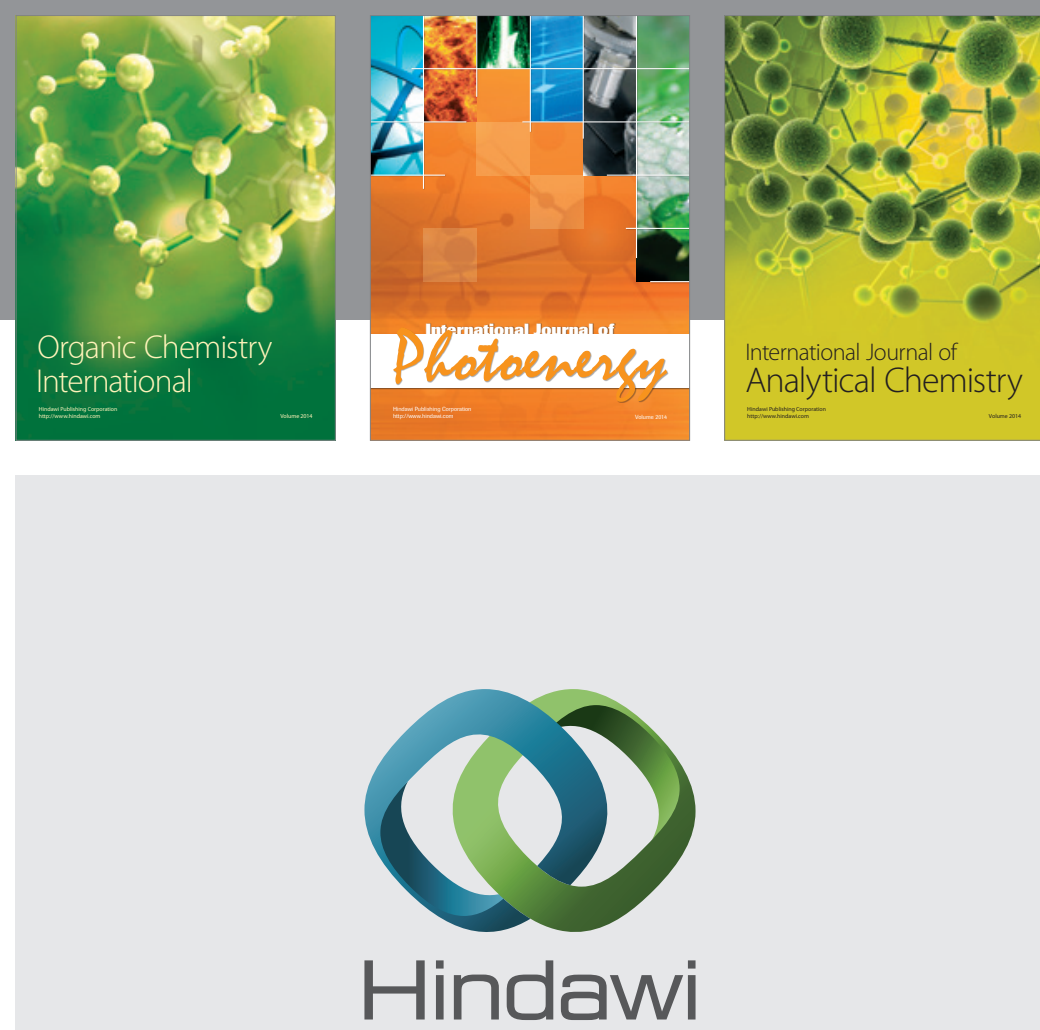

Submit your manuscripts at

http://www.hindawi.com
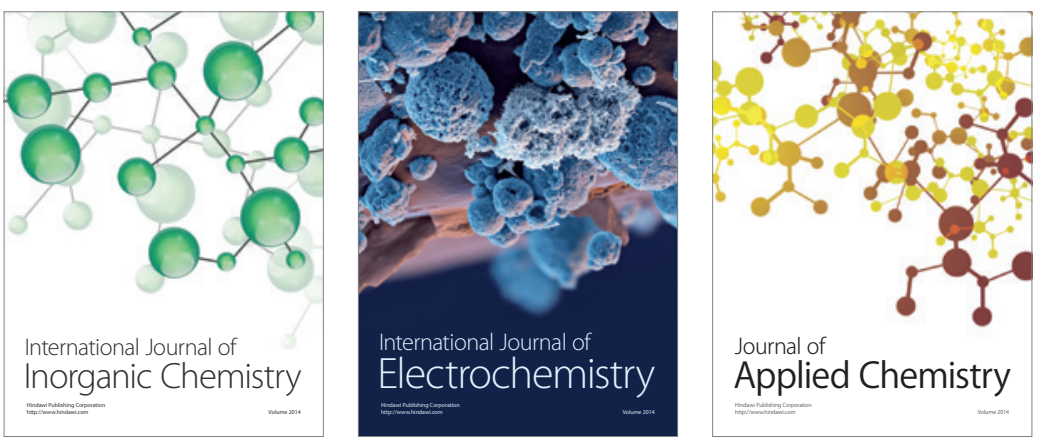

Journal of

Applied Chemistry
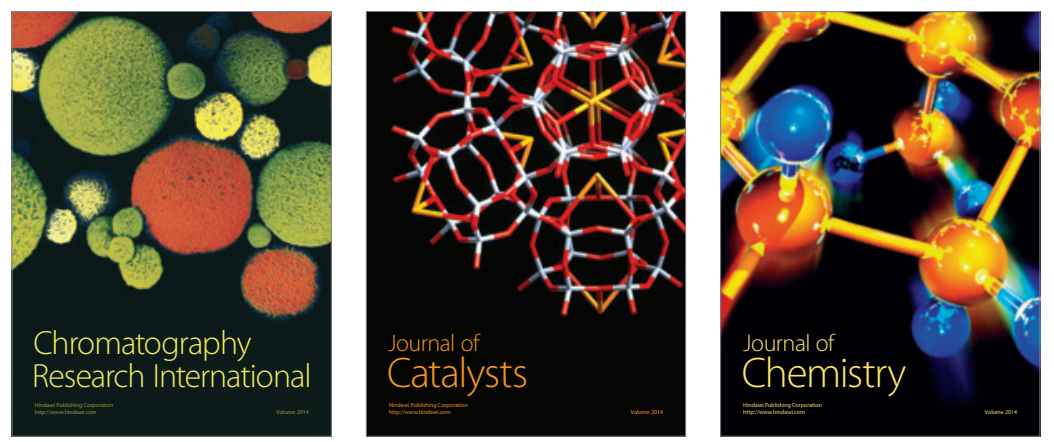
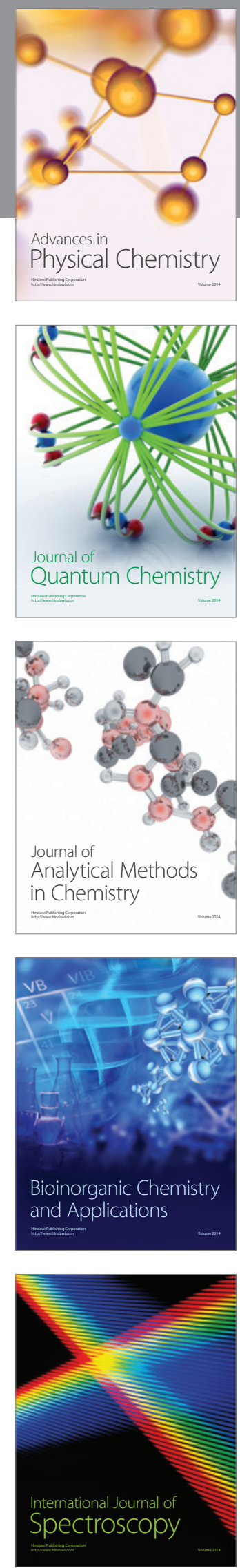